\title{
A Novel Integrated AHP-QFD Model for Software Project Selection under Fuzziness
}

\author{
Tuli Bakshi \\ Research Scholar \\ Jadavpur University \\ Kolkata, India
}

\author{
Bijan Sarkar \\ Professor \\ Jadavpur University \\ Kolkata, India
}

\author{
Subir Kumar Sanyal \\ Professor \\ Jadavpur University \\ Kolkata,India
}

\begin{abstract}
Now-a-days software manufacturing companies usually try to capture market share with rapid software development. Actually the development of high quality software products can decrease cost by reducing rework and increasing productivity. For that, reason selection of software projects is an important task. Several factors come into consideration while selection of proper project for a specified job. To deal with this typical situation the current researchers combined the much known AHP(Analytic Hierarchy Process) with QFD (Quality Function Deployment). Here the AHP method redefined under fuzziness. Then QFD process is applied to identifying and ranking customer's need and translating them into product / service specification. At the last sensitivity analysis has been done to make the process more robust from the characterization of integration of the fuzzy AHP \& QFD.
\end{abstract}

\section{General Terms}

Software project selection; fuzziness; sensitivity analysis.

\section{Keywords}

Quality Function Deployment; AHP; Fuzziness; Project selection .

\section{INTRODUCTION}

Project selection is the process of evaluating individual projects or group of projects and then choosing the most viable project for implementation, so that the objectives of the parent organization will be achieved in due time. This systematic process of project selection can be applied to any area of the organization's business in which choices must be made between competing alternatives. Each project will have different costs, benefits and risks. Rarely these are known with certainty. In the face of such differences, the selection of one project out of a set of projects is a difficult task. Choosing a number of different projects, a portfolio, is even more complex.

Project selection is only one of many decisions associated with project management. The proper choice of investment in projects is crucial to the long-run survival of every organization. This type of decision involves multiple factors such as identification, considerations and analysis of viability. According to Hwang and Yoon [1] Multi-criteria decision making (MCDM) is applied to preferable decisions among available classified alternatives by multiple attributes. So MCDM is one of the most widely used decision methodology in project selection problems [2]. The MCDM is a method that follows the analysis of several criteria, simultaneously. In this method economic, environmental, social and technological factors are considered for the selection of the project and for making the choice sustainable [3-5].Several framework have been proposed for solving MCDM problems, namely Analytical Hierarchy Process [AHP] [6, 7, 8], Analytical Network Process [ANP] [9], which deals with decisions in absence of knowledge of the independence of higher level elements from lower level elements and about the independence of the elements within a level. Other framework available are data envelopment analysis ( DEA),Technique for order performance by similarity to ideal solution (TOPSIS) [11],VIKOR [12,13], MOORA [14,15],COPRAS [16], with grey number,[17-19],Simple Additive weighting ( SAW) etc [20], LINMAP [21].With these techniques alternative ratings are measured, weight of the criteria are expressed in précised numbers [22]. The projects' life cycle assessment is to be determined and the impact of all actors is to be measured. There are some mandatory axioms that the criteria describing feasible alternatives are dimensions, which are important to determine the performance.

The present work encompasses technical requirements, customer's requirements and economics of the selection of projects in customer's perspective. In this paper, current researchers develop an integrated novel technique for the economics of project selection.

\section{RELATED WORKS}

In available DSS methods, application of the AHP [23-29] to the project selection problem is not now in the art. Among formal decision tools' Satty's analytic network process (ANP) model [30] is assumed to be suitable for the project evaluation process. On the contrary, some researchers [31-33] have iterated that to integrate the cardinal and ordinal preferences using ANP/ AHP for project selection decisions are not valid. In the research paper, project selection and evaluation studies have been carried under fuzziness [34-37]. Fuzzy methods were applied to the multi attribute selection models [38-39]. Sevkli et al. [40] have proposed a method of project selection combining AHP and fuzzy LP. The weights of the project selection criteria are measured using AHP method.

Several types of integrated QFD technique [41] have been used in determining as well as ranking candidate supplier. Researchers are proposed the introduction of Fuzzy technique [42] for selection of processes. There have been constant efforts to integrate AHP with QFD to establish a framework for prioritizing customer requirements and hence to select appropriate projects [43-45]. In one such integrated technique, QFD is experimented to develop criteria with corresponding evaluating weights where in AHP is used in two phases [46]. In first phase to measure the relative importance's weighting for each project and in second phase to evaluate the score for each of the alternatives to each particular criterion. 


\section{THEORY OF FUZZY AHP \& QFD 3.1 Fuzzy Sets Theory and Fuzzy AHP}

Zadeh [47] first introduced the fuzzy set theory to deal with vagueness of human thought, which was oriented to the rationality of uncertainty due to imprecision or vagueness. The fuzzy sets actually represent the vague data. The theory also allows mathematical operators and programming to apply to the fuzzy domain. Fuzzy sets consist of a class of objects with a continuum of grades of membership functions. Such membership functions are ranging between zero and one. A tilde ': ' will be placed above a symbol for representing a fuzzy sets. Therefore $x^{\prime}, y^{\prime}, Z^{\circ}$ are fuzzy sets. The membership functions for these fuzzy sets will be denoted by $\mu(p \mid \mathcal{X})$ and $\mu(p \mid z)$ respectively. A triangular fuzzy number (TFN), $\stackrel{\rho}{\mu}$ is shown in fig1. A TFN is denoted as $\left(\mathrm{m}_{1}, \mathrm{~m}_{2}, \mathrm{~m}_{3}\right)$. The parameters $\mathrm{m}_{1}$ denotes the smallest possible value, $m_{2}$ the most promising value and $m_{3}$ describes the largest possible value of a fuzzy event.

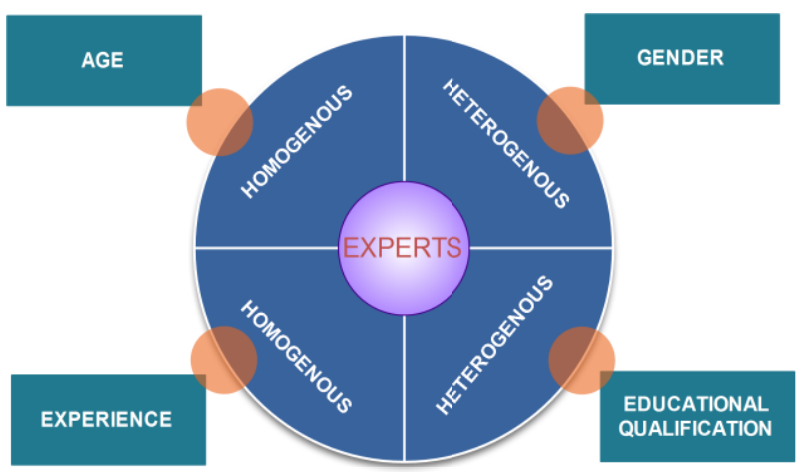

Fig 1: Classification of Experts

AHP is a useful technique for analyzing complex multiple criteria alternatives using subjective judgment. For calculating the importance of the criteria a decision-maker determines the weight of the alternatives by conducting pair-wise comparisons between criteria. But the conventional AHP can not fully reflect the human thinking style [48]. Linguistic and vague descriptions could not be solved easily by AHP until the recent development in fuzzy decision -making [49]. The fuzzy AHP approach can be used as an advanced analytical method developed from the traditional AHP. The first study of fuzzy AHP was proposed by Van Laarhovan and Pedrycz [50] in which triangular fuzzy numbers are used. Later on Chang [51] introduced a new approach for handling fuzzy AHP, with the use of triangular fuzzy numbers and the use of the extent analysis method for the synthetic extent values of the pairwise comparisons. Fuzzy pair-wise comparisons are more rational to represent decision- makers' or experts' uncertain judgments with comparison to crisp ones. In our present project selection approach the decision makers' tend to give assessments based on their expertise knowledge of the domain. In general linguistic variables such as "most important", "important", "less important" are used to make the experts' assessments. Experts are categorized as described in figure 1. In conclusion, it can be said that by incorporating fuzzy set theory with AHP, fuzzy AHP allows a more accurate description of the decision making process.

\subsection{QFD (Quality Function Deployment)}

Historical background on QFD has depicted that it was originally evaluated in 1972 in Japan, as a technique that was used to improve product quality in Japanese firms, such as Toyota, Mitsubishi and their suppliers [52]. Toyota was able to decrease startup production costs by $60 \%$ from 1977 to 1984 and shortened the time required for its development by one-third through the use of QFD [52-53].

The basic concept of QFD is to deliver a means of defining, customer requirements and translating them into the appropriate technical requirements and actions for each stage of the product / software development cycle, and a customer satisfactory product can be gained by coordinating every activity in an organization. Generally QFD process consists of two stages : capturing customer requirement and the waterfall decomposition process of the customer requirements. In the first phase, the QFD team members (experts) use all technique available to gather or collect the customer requirements i.e, what the customer really wants and expects for the product or model being designed, and then analyze them. This phase is the most critical and also the most difficult part of the QFD process. In the second phase, the QFD team members use a graphic- based tool known as House of Quality (HOQ) to translate the customer's requirements into technical requirements. House of Quality (HOQ) used in each translation is a chart that is made up of information on "What to do in relation to CRs", "How CRs are related to TRs" and relationships between CRs and TRs. It includes among the TRs, benchmarking data, attributes' data and prioritization information. The typical structure of the HOQ is shown as fig1 below:
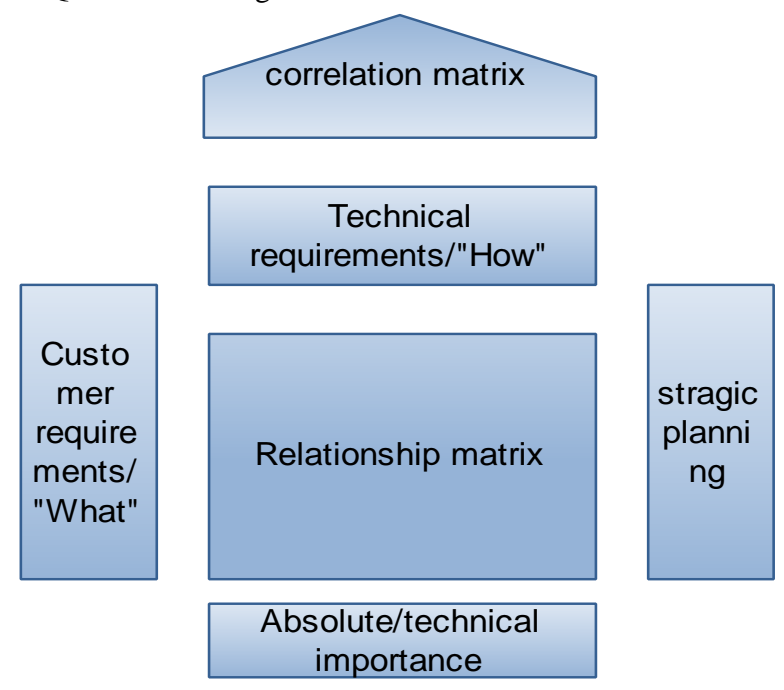

Fig 2: Diagram of QFD

Taking into consideration, the first HOQ as an example, the process of constructing a HOQ includes the following tasks:

- Identify the customer requirements ( "Whats"), their relative importance, their improvement ratios and target levels;

- Identify the technical requirements ( "Hows");

- Identify the relationship between "Whats" and "Hows";

- Identifying the corelation between "Hows";

- Determining the importance, improvement ratios and target values for product / software characteristics.

So, it can be inferred that QFD provides a structure to the front end process. It is a systematic procedure for identifying 
and ranking customer needs, translating those needs into product / service specifications and tracking those customer needs throughout the product / service realization process.

\section{PROPOSED WORK}

The methodology adopted in this research work is directed to determine as well as rank the projects among a set of alternative projects. The current researchers have considered the project selection technique from the perspective of customer requirement combining the technical feasibility and economic profitability. The current researchers have used AHP under fuzziness for determining the degrees of relative importance for customer requirement and QFD for determining the degrees of relative importance and normalized importance of each technical requirement. An overall score for individual project is then calculated for the decision maker to choose most appropriate based upon multiple criteria that may be conflicting in nature.

Though the basic reasons for the implementation of a project selection system in customer's perspective are to enhance profitability and quality, the ultimate justification is to be made in economic terms. For that purpose there is a need to make the proposed combined Fuzzy AHP/ QFD model more robust. Understanding the affect of change in criteria values and model structure an optimum solution is derived by sensitivity analysis. The current researchers have considered cost factors as parametric values for sensitivity analysis.

\section{ALGORITHM}

\subsection{Fuzzy AHP}

The fuzzy AHP technique can be viewed as an advanced analytical method developed from the traditional AHP. According to the method of Chang's (1992) [51] extent analysis, each criterion is taken and extent analysis for each criterion, $g_{i}$ 's performed on, respectively. Therefore, m extent analysis values for each criterion can be obtained by using following notation :

$M_{g_{i}}^{1}, M_{g_{i}}^{2}, M_{g_{i}}^{3}, M_{g_{i}}^{4}, M_{g_{i}}^{5}$ $M_{g_{i}}^{m}$,where

$g_{i}$ is the goal set $(\mathrm{i}=1,2,3,4, \ldots \ldots \ldots \ldots \ldots \ldots . . . \mathrm{n})$ and all $M_{g_{i}}^{j}(\mathrm{j}=$ $1,2,3,4, \ldots \ldots . . . m$ ) are Triangular Fuzzy Numbers( Tens). The steps of the analysis can be given as follows:

Step 1:- The fuzzy synthetic extent value $\left(S_{i}\right)$ with respect to the ith criterion is defined as equation (1):-

$$
S_{i}=\sum_{j=1}^{m} M_{g_{i}}^{j} \otimes\left(1 /\left[\sum_{i=1}^{n} \sum_{j=1}^{m} M_{g_{i}}^{j}\right]\right)
$$

To obtain (2):- $\quad \sum_{j=1}^{m} \boldsymbol{M}_{g_{i}}^{j}$

Perform the fuzzy addition operation of $m$ extent analysis values for a particular matrix given in equation (3) below, at the end step of calculation, new $(\mathrm{l}, \mathrm{m}$, and $\mathrm{u})$ set is obtained and used for the next:-

$\sum_{j=1}^{m} M_{g_{i}}^{j}=\left(\sum_{j=1}^{m} l_{j}, \sum_{j=1}^{m} m_{j}, \sum_{j=1}^{m} u_{j}\right)$

Where 1 is the lower limit value, $\mathrm{m}$ is the most promising value and $u$ is the upper limit value and to obtain (4):-

$$
\left(1 /\left[\sum_{i=1}^{n} \sum_{j=1}^{m} M_{g_{i}}^{j}\right]\right)
$$

Perform the fuzzy addition operation of $M_{g_{i}}^{j}$ (j =1, 2, 3, 4 ...m) values given as equation (5):-

$$
\sum_{i=1}^{n} \sum_{j=1}^{m} M_{g_{i}}^{j}=\left(\sum_{i=1}^{n} l_{i}, \sum_{i=1}^{n} m_{i}, \sum_{i=1}^{n} u_{i}\right)
$$

And then compute the inverse of the vector in the equation (5) and equation (6) is then obtained as:-

$$
\left(\frac{1}{\left[\sum_{i=1}^{n} \sum_{j=1}^{m} M_{g_{i}}^{j}\right]}\right)=\left(\frac{1}{\sum_{i=1}^{n} u_{i}}, \frac{1}{\sum_{i=1}^{n} m_{i}}, \frac{1}{\sum_{i=1}^{n} l_{i}}\right)
$$

Step 2:-The degree of possibility of

$M_{2}=\left(l_{2}, m_{2}, u_{2}\right) \geq M_{1}=\left(l_{1}, m_{1} u_{1}\right)$ is defined as equation (7):-

$\mathrm{V}\left(M_{2} \geq M_{1}\right)=\sup \left[\min \left(\mu_{M 1}(\mathrm{x}), \mu_{M 2}(\mathrm{y})\right)\right]$

$$
\mathrm{y} \geq \mathrm{x}
$$

And $\mathrm{x}$ and $\mathrm{y}$ are the values on the axis of membership function of each criterion. This equation can be written as :

$$
\begin{aligned}
\mathrm{V}\left(M_{2} \geq M_{1}\right) & =1, \quad \text { if } m_{2} \geq m_{1} \\
= & 0, \quad \text { if } l_{1} \geq u_{2} \\
& =\frac{l_{1}-u_{2}}{\left(m_{2}-u_{2}\right)-\left(m_{1}-l_{1}\right)}, \text { otherwise }
\end{aligned}
$$

Step 3:-The degree possibility for a convex fuzzy number to be greater than $\mathrm{k}$ convex fuzzy numbers $M_{i}$ (i= 1 , $2,3,4,5 \ldots \ldots \ldots \ldots \ldots . . . . k)$ can be defined by

$$
\mathrm{V}\left(\mathrm{M} \geq M_{1}, M_{2}, M_{3} \ldots \ldots \ldots \ldots \ldots . . . M_{k}\right)=\min \mathrm{V}
$$

$\left(\mathrm{M} \geq M_{i}\right), \mathrm{i}=1,2 \ldots \mathrm{k}$. Assume that equation (9) is

$$
d^{*}\left(A_{i}\right)=\min \mathrm{V}\left(S_{i} \geq S_{k}\right)
$$

For $\mathrm{k}=1,2,3 \ldots \ldots \ldots \ldots \ldots . . \mathrm{n} ; \mathrm{k} \neq \mathrm{i}$. Then the weight vector is given by equation (10):-

$$
W^{*}=\left(d^{*}\left(A_{1}\right), d^{*}\left(A_{2}\right), \ldots \ldots \ldots \ldots . . d^{*}\left(A_{n}\right)\right) \mathrm{T}
$$

Where $A_{i}(\mathrm{i}=1,2,3 \ldots \mathrm{n})$ are $\mathrm{n}$ elements.

Step 4:-Via normalization, the normalized weight vectors are given in equation 11:-

$\mathrm{W}=\left(\mathrm{d}\left(A_{1}\right), \mathrm{d}\left(A_{2}\right), \mathrm{d}\left(A_{3}\right) \ldots \mathrm{d}\left(A_{n}\right)\right)^{\mathrm{T}}$

Where $\mathrm{W}$ is non-fuzzy numbers.

Schematic diagram for Fuzzy AHP is given below:

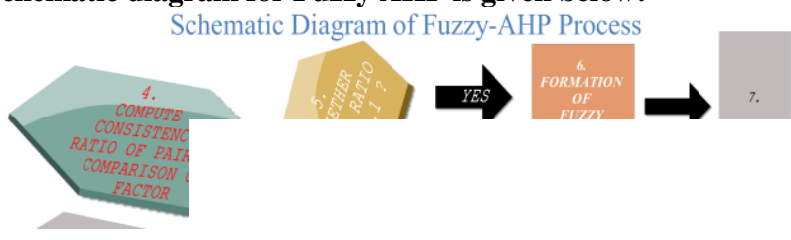




\subsection{Quality Function Deployment:-}

Step1:- Construction of central relationship matrix using expertise knowledge of QFD team by combining the Customer's requirements and the technical requirements.

Step 2:- Compute the degree of importance for Customer's requirements by Fuzzy AHP method.

Step 3:- Compute the degree of technical requirements using $w_{j}=\sum_{i=1}^{m} R_{i j} c_{i}$, where $w_{j}$ is the degree of importance for the $\mathrm{j}^{\text {th }}$ technical requirement $(\mathrm{j}=1,2, \ldots \ldots \ldots . . . \mathrm{n}) ; \quad R_{i j} \quad$ is the relationship between the $\mathrm{i}^{\text {th }}$ customer requirement and the $\mathrm{j}^{\text {th }}$ technical criteria in the central relationship matrix; and $c_{i}$ is the importance weighing of the $i^{\text {th }}$ customer requirement.

Step 4:- Normalize the degree of importance of technical criteria by

$$
\overline{w_{j}}=\frac{w_{j}}{\sum_{j=1}^{n} w_{j}} \times 100
$$

Step 5:- Construct the pair wise comparison matrices for each technical requirement using Satty's $[42,43]$ nine -point scale.

Step 6:- Evaluation of score, $c_{i j}$, for each technical requirement for each alternative project.

Step 7:- Compute the overall score by

$S_{j}=\sum_{j=1}^{n} \overline{w_{j}} c_{i j}$, where $S_{j}$ is the overall score for the $\mathrm{j}^{\text {th }}$ alternative project( $\mathrm{j}=1,2, \ldots \ldots \ldots \ldots . .$.$) ; \overline{w_{j}}$ is the normalized importance degree of the $j^{\text {th }}$ technical criteria $(j=1,2, \ldots . . . n)$; and $e_{i j}$ is the PV value of the $\mathrm{j}^{\text {th }}$ alternative on the $\mathrm{i}^{\text {th }}$ technical criteria.

Step 8:- Ranking of all the alternative projects and select the best one using the analogy 'the higher the score, the better the selection' [54].

\section{Schematic diagram for Proposed Fuzzy AHP/ QFD Model} is given below:

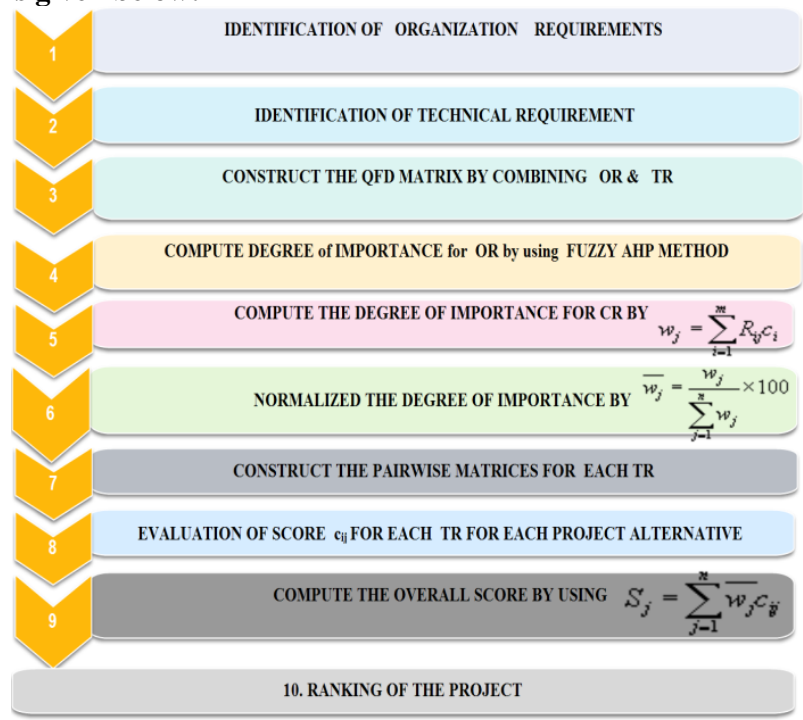

Figure 4. Diagram for Proposed Fuzzy AHP/ QFD Model

\section{CASE STUDY}

A case study of a software company dealing with an enormous volume of projects analyzed here to benchmark the proposed method [55]. The identified customer requirements for a particular project selection process are Realism, Capability, Flexibility and cost.

- Realism: - The project should reflect the reality of the customer's decision situation, including the multiple objectives of both the organization and its customer. It includes the factors that reflect project risks (technical risks and implementation risks)

- $\quad$ Capability: - The project should deal with multiple time periods, simulate various situations both internal and external to the project.

- $\quad$ Flexibility: - The project should have the ability to be easily modified or to be self-adjusting in response to changes in the customer requirement.

- Cost: - All types of costs (Design cost, Implementation cost, Installation Cost, Maintenance cost) should be low and must surely be less than the potential benefits of the project.

These are denoted by $r_{1}, r_{2}, r_{3}, r_{4}$. Correspondingly, four technical requirement factors have been identified: Project risks, Project time, Adaptability and Project Cost. The factors may be denoted by $f_{1}, f_{2}, f_{3}, f_{4}$. The job is to select the best one of four projects.

The central relationship matrix displaying the degree of relationship between each customer requirement and the corresponding technical requirement is constructed. A decision matrix (table1) and a Fuzzy evaluation matrix (table2) by expert's opinion is constructed to measure the relative degree of importance for each customer requirement, based on the proposed methodology.

The PV values of this decision matrix is obtained as [0.29, $0.34,0.23,0.14]^{\mathrm{T}}$. To check the level of inconsistency the results obtained are: $\quad \lambda \max =4.1287$; C.I. $=0.0429 ;$ R. I. $=$ 0.99 and $C_{R}=0.43$. The QFD team puts the PV values into the transformation matrix shown in table 3 .

\subsection{Calculation of PV values by Fuzzy AHP}

\begin{tabular}{|l|l|l|l|l|}
\multicolumn{1}{c}{ TABLE I. } & \multicolumn{1}{l}{ EVALUAT ION MATRIX } \\
\hline Criteria & A & B & C & D \\
\hline A & 1 & 1 & 2 & 1 \\
\hline B & 1 & 1 & 2 & 2 \\
\hline C & 0.5 & 1 & 1 & 1.33 \\
\hline D & 0.5 & 0.5 & 0.75 & 1 \\
\hline
\end{tabular}


TABLE II. Fuzzy Evaluation Matrix

\begin{tabular}{|c|c|c|c|c|}
\hline Criteria & A & B & C & D \\
\hline A & $(1,1,1)$ & $(0.75,1,1.25)$ & $(1,2,3)$ & $(0.75,1,1.25)$ \\
\hline B & $(0.8,1,1.33)$ & $(1,1,1)$ & $(1,2,3)$ & $(1.33,2,4)$ \\
\hline C & $(0.33,0.5,1)$ & $(0.8,1,1.33)$ & $(1,1,1)$ & $(1,1.33,2)$ \\
\hline D & $(0.25,0.5,0.75)$ & $(0.33,0.5,1)$ & $(0.5,0.75,1)$ & $(1,1,1)$ \\
\hline
\end{tabular}

Now calculating all the values by applying Chang's [51] theory the following results are obtained:

$\mathrm{S}_{\mathrm{A}}=(3.5,5,6.5) \otimes(0.04,0.057,0.078)=(0.14,0.28,0.51)$

$\mathrm{S}_{\mathrm{B}}=(4.13,6,9.33) \otimes(0.04,0.057,0.078)=(0.17,0.34,0.73)$

$\mathrm{S}_{\mathrm{C}}=(3.13,3.83,5.33) \otimes(0.04,0.057,0.078)=(0.13,0.22,0.42)$

$\mathrm{S}_{\mathrm{D}}=(2.08,2.75,3.75) \otimes(0.04,0.057,0.078)=(0.08,0.16,0.29)$

$\mathrm{V}\left(\mathrm{S}_{\mathrm{A}} \geq \mathrm{S}_{\mathrm{B}}\right)=0.85, \mathrm{~V}\left(\mathrm{~S}_{\mathrm{A}} \geq \mathrm{S}_{\mathrm{C}}\right)=1$,

$\mathrm{V}\left(\mathrm{S}_{\mathrm{A}} \geq \mathrm{S}_{\mathrm{D}}\right)=1$

$\mathrm{V}\left(\mathrm{S}_{\mathrm{B}} \geq \mathrm{S}_{\mathrm{A}}\right)=1, \mathrm{~V}\left(\mathrm{~S}_{\mathrm{B}} \geq \mathrm{S}_{\mathrm{C}}\right)=1$,

$\mathrm{V}\left(\mathrm{S}_{\mathrm{B}} \geq \mathrm{S}_{\mathrm{D}}\right)=1$

$\mathrm{V}\left(\mathrm{S}_{\mathrm{C}} \geq \mathrm{S}_{\mathrm{A}}\right)=0.82 \mathrm{~V}\left(\mathrm{~S}_{\mathrm{C}} \geq \mathrm{S}_{\mathrm{B}}\right)=0.67$,

$\mathrm{V}\left(\mathrm{S}_{\mathrm{C}} \geq \mathrm{S}_{\mathrm{D}}\right)=1$

$\mathrm{V}\left(\mathrm{S}_{\mathrm{D}} \geq \mathrm{S}_{\mathrm{A}}\right)=0.55, \mathrm{~V}\left(\mathrm{~S}_{\mathrm{D}} \geq \mathrm{S}_{\mathrm{B}}\right)=0.4$,

$\mathrm{V}\left(\mathrm{S}_{\mathrm{D}} \geq \mathrm{S}_{\mathrm{C}}\right)=0.73$

Minimum of all values $(0.85,1,0.67$, and 0.4$)$

The weight $\mathrm{W}=(0.29,0.34,0.23,0.14)$

$\mathrm{A}=$ Realism $\mathrm{B}=$ Capability $\mathrm{C}=$ Flexibility $\mathrm{D}=$ Cost

The next job of the QFD team is to find out the ranking of the four given projects based upon the four conflicting TR. The following four pair wise comparison matrices are produced based on the information on each TR.

Matrix1: For 'Project risk' criterion:

$$
\mathrm{A}_{1}=\left(\begin{array}{cccc}
1 & 5 & 2 & 8 \\
\frac{1}{5} & 1 & \frac{1}{5} & 2 \\
\frac{1}{2} & 5 & 1 & 4 \\
\frac{1}{8} & \frac{1}{2} & \frac{1}{4} & 1
\end{array}\right)
$$

Matrix 2: For 'Project time' criterion:

$\mathrm{A}_{2}=\left(\begin{array}{cccc}1 & \frac{1}{2} & \frac{1}{4} & 3 \\ 2 & 1 & \frac{1}{2} & 5 \\ 4 & 2 & 1 & 7 \\ \frac{1}{3} & \frac{1}{5} & \frac{1}{7} & 1\end{array}\right)$
Matrix 3: For 'Adaptability' criterion:

$$
\mathrm{A}_{3}=\left(\begin{array}{cccc}
1 & \frac{1}{5} & \frac{1}{2} & \frac{1}{4} \\
5 & 1 & 4 & 3 \\
2 & \frac{1}{4} & 1 & \frac{1}{5} \\
4 & \frac{1}{3} & 5 & 1
\end{array}\right)
$$

Matrix 4 : For 'Project Cost' criterion :

$$
\mathrm{A}_{4}=\left(\begin{array}{cccc}
1 & \frac{1}{3} & 5 & 3 \\
3 & 1 & 6 & 5 \\
\frac{1}{5} & \frac{1}{6} & 1 & \frac{1}{4} \\
\frac{1}{3} & \frac{1}{5} & 4 & 1
\end{array}\right)
$$

TABLE III.

QFD MATRIX FOR PROJECT SELECTION PROBLEM

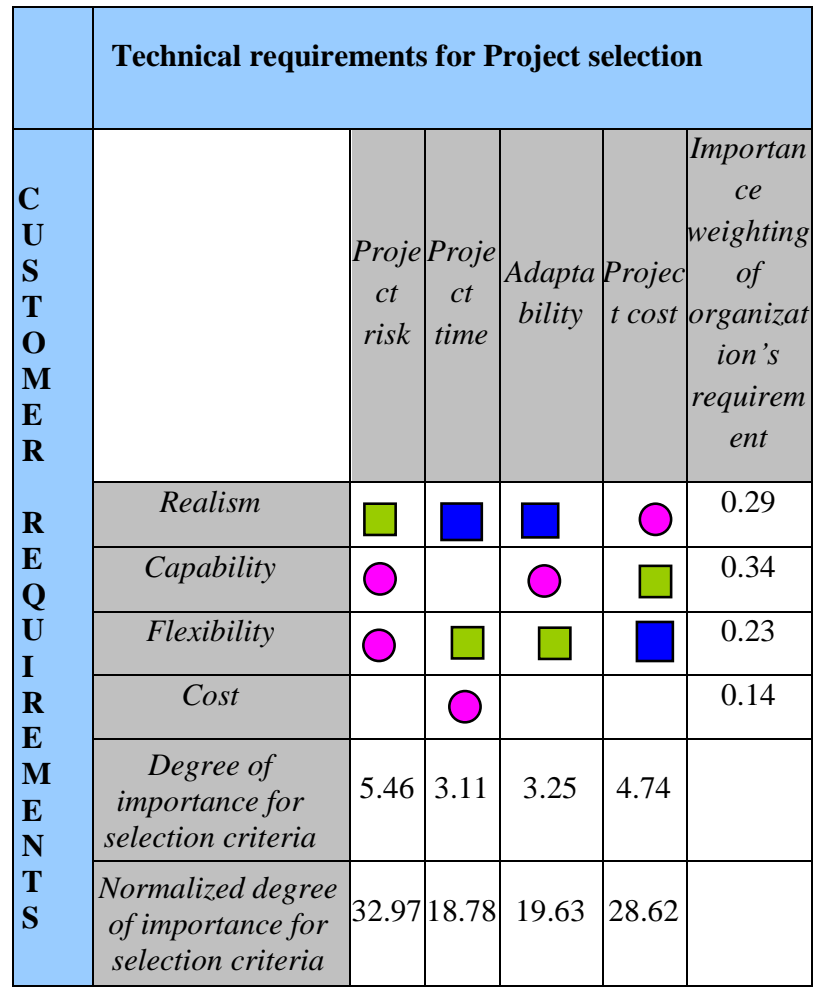

Strong 9: $\square$ MODERATE 5; $\bigcirc$ WEAK 1; $\square$ BLANK : No

TABLE IV. OVERALl SCORES OF THE FOUR PROJECTS

\begin{tabular}{|l|l|l|l|l|l|}
\hline \multirow{2}{*}{$\begin{array}{l}\text { Technical } \\
\text { requirements }\end{array}$} & \multicolumn{5}{|c|}{ Importance weight for Projects } \\
\cline { 2 - 6 } & Weight & $P_{1}$ & $P_{2}$ & $P_{3}$ & $P_{4}$ \\
\hline Project risk & 32.97 & 0.529 & 0.094 & 0.314 & 0.062 \\
\hline Project time & 18.78 & 0.147 & 0.280 & 0.514 & 0.059 \\
\hline Adaptability & 19.63 & 0.074 & 0.520 & 0.105 & 0.300 \\
\hline Project cost & 28.62 & 0.267 & 0.550 & 0.054 & 0.128 \\
\hline Overall Score & & 29.30 & 34.31 & 23.61 & 12.70 \\
\hline
\end{tabular}

So $\mathbf{P}_{\mathbf{2}}>\mathbf{P}_{\mathbf{1}}>\mathbf{P}_{\mathbf{3}}>\mathbf{P}_{\mathbf{4}}$ i.e. $\mathrm{P}_{2}$ has precedence over $\mathrm{P}_{1}$ which is more important than $\mathrm{P}_{3}$ and $\mathrm{P}_{4}$ Thus the project $\mathrm{P}_{2}$ is selected, as it has the highest overall score.

\subsection{Involvement of cost-factor measures}

Though the basic reasons for the implementation of selection of projects are to enhance profitability and quality, the ultimate justification is to made in economic terms. Thus, there is a need to make the proposed combined Fuzzy AHP / QFD model more robust. Project selection should consider 
cost factors. The sensitivity analysis is done to prove the robustness of the project selection.

The total cost of the project selection system described in the present case study may be broken down as shown in table 5 . The cost factors in table 5 involve two types of costs, both fixed and recurring types. The attributes of the cost components are listed in table 6 for four different projects.

\section{TABLE $\mathrm{V}$ COST-FACTOR COMPONENTS AND THEIR UNITS}

\begin{tabular}{|l|c|}
\hline Cost-factor components & Range of attribute values ( US \$ ) \\
\hline 1. Design Cost & $4000-9000$ \\
\hline 2. Implementation Cost & $4000-12000$ \\
\hline 3. Installation Cost & $1000-2100$ \\
\hline 4. Maintenance Cost & $900-2100$ \\
\hline
\end{tabular}

Schematic diagram [55] for Sensitivity Analysis is given below

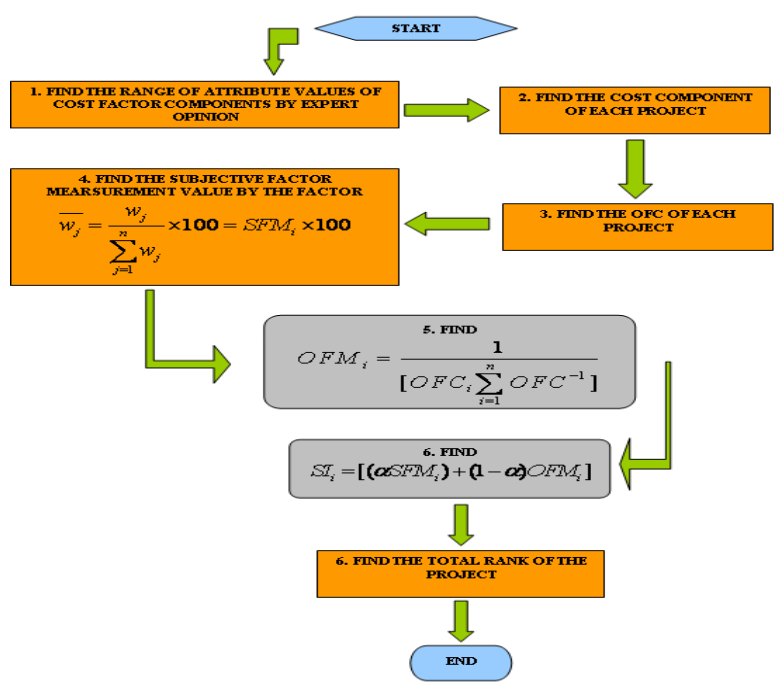

Figure 5 diagram [55] for Sensitivity Analysis

A mathematical model was proposed by Bhattacharya et al. [56-58] to combine cost-factor components with the importance weightings found from Fuzzy AHP, The equation of the stated model is:

$$
\begin{aligned}
& S I_{i}=\left[\left(\alpha S F M_{i}\right)+(1-\alpha) O F M_{i}\right] \\
& \text { where } \mathrm{OFM}_{i}=\frac{1}{\left[O F C_{i} \sum_{i=1}^{n} O F C^{-1}\right]}
\end{aligned}
$$

where OFM is the Objective Factor Measure, OFC is the Objective Factor Cost, SFM is the Subjective Factor Measure, $\mathrm{SI}$ is the selection Index, $\alpha$ is the Objective factor decision weight, and $n$ is the number of alternative projects $(n=4$ in the present case).

\begin{tabular}{|c|c|c|c|c|}
\hline \multirow{2}{*}{ Cost Components } & \multicolumn{4}{|c|}{ Projects } \\
\hline & $P_{1}$ & $P_{2}$ & $\boldsymbol{P}_{3}$ & $P_{4}$ \\
\hline 1. Design Cost & 7500 & 4000 & 6800 & 9000 \\
\hline $\begin{array}{l}\text { 2. Implementation } \\
\text { Cost }\end{array}$ & 8600 & 4193 & 6975 & 12000 \\
\hline 3. Installation Cost & 1900 & 1065 & 1400 & 2100 \\
\hline $\begin{array}{l}\text { 4. Maintenance } \\
\text { Cost }\end{array}$ & 1487 & 908 & 940 & 2023 \\
\hline Total ( OFC) (US \$) & 19487 & 10166 & 16115 & 25123 \\
\hline
\end{tabular}

TABLE VI. ATTRIBUTES OF COST FACTOR COMPONENTS

SFM values are the ordinal measures of customer requirements found using Fuzzy AHP. OFCs are the total costs of each project. The value of $\alpha$ depends on the decision-maker's preference regarding the importance of objective and subjective factor measures.

Thus, a sensitivity plot to analyze the effect of $\alpha$ in the project selection problem is strongly recommended.

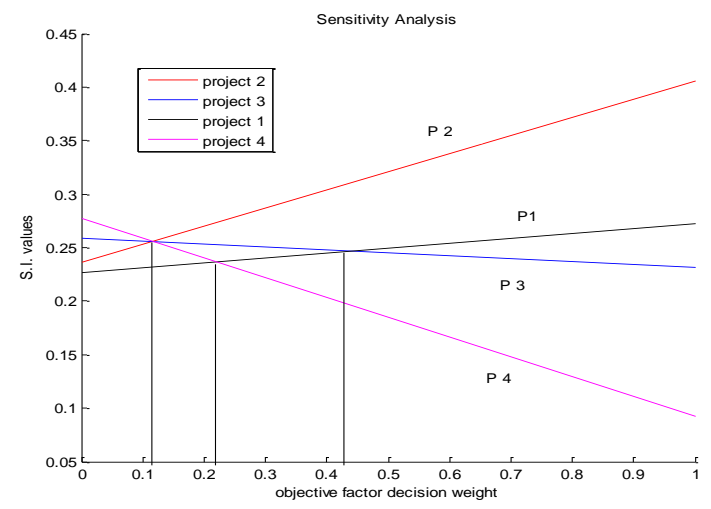

Figure 6 sensitivity plot to analyze

Considering $\alpha=0.43$, the project alternatives are ranked as: $\mathbf{P}_{\mathbf{2}}>\mathbf{P}_{\mathbf{1}}>\mathbf{P}_{\mathbf{3}}>\mathbf{P}_{\mathbf{4}}$, which is similar to that found from Table 4 .

\section{CONCLUSION}

Project selection is a multi-criteria decision making problem. In this paper the selection is performed in three phases. The first phase (i.e., pre-qualification selection), a set of alternatives are selected by the proposed fuzzy method. This method can handle qualitative and quantitative criteria. In the second phase (i.e., final selection) quality function deployment (QFD) is utilized to select the best option. QFD is a unique tool considering the relationship between customer requirement and technical requirement criteria. In addition, linguistic variables and triangular fuzzy numbers are used to overcome the vagueness in human thoughts. Lastly in the third phase (i.e., the post final testing) sensitivity analysis have been derived. It ensures the robustness of the selection methodologies and the viability of the selection from the economic point of view. It is worth to apply this integrated method to compare the 
efficiency between project selection criteria and software engineering development characteristics.

\section{REFERENCES}

[1] C.L.Hwang \& K.P.Yoon, "Multiple Attribute Decision Making and Introduction", London, Sage Publication, (1995) pp2.

[2] Bakshi, T., Sarkar, B., "MCA based performance evaluation of project selection",Int.J. Of Software Engineering and Applications (IJSEA), Vol.2, No.2, April 2011.

[3] Lombera J. T. S. J., Rojo J.C, "Industrial building design stage based on a system approach to their environmental sustainability", Construction and Building Materials, (2010), Vol. 24, No. 4, pp. 438-447.

[4] Lombera J.-T. S.-J., Aprea I.G, "A system approach to the environmental analysis of industrial buildings", Building and Environment, (2009) Vol. 45, No. 3, pp. 673-683.

[5] Juan Y.-K., Gao P., Wang I "A hybrid decision support system for sustainable office building renovation and energy performance improvement", Energy and Buildings, (2010), Vol. 42, No. 3, pp. 290-297

[6] Morkvenas, R;Bivainis J; Jarzemsks,A, “Assessment of employee's knowledge potential in transport sector", Transport 23(3), (2008), 258-265.

[7] Maskeliunaite, L; Sivilevicius, H; Podvezko, V, "Research on the quality of passenger transportation by railway", Transport 24 (2), .(2009), 100-112.

[8] Saaty T.L, The Analytic Hierarchy Process: Planning, Priority Setting, Resource Allocation. Mcgraw-Hill. .(1980), 287p.

[9] Satty T.L., the Analytic Network Process. RWS Publications Pittsburgh. (1996).

[10] Hwang, C.L; Yoon, K., "Multiple Attribute Decision Making: Methods and Applications", A state of the Art Survey. .(1981), $1^{\text {st }}$ edition. Springer. 259p

[11] Wang, T.C; Lee, H-D. , "Developing a fuzzy TOPSIS approach based on subjective weights and objective weights", Expert Sustems with Applications, (2009), 36 (5): 8980-8985.

[12] Datta, S., Beriha, G.S., Patnaik,B., Mahapatra, S.S., "Use of compromise ranking method for supervisor selection: A multi-criteria decision making (MCDM) approach", International Journal of Vocational and Technical Education, .(2009),vol.1(1),pp.007-013.

[13] Bskshi, T.,SinhaRay, A., Sarkar, B.,Sanyal, S.K., " MCDM Based Project Selection by F-AHP \& VIKOR", SEMCCO 2011, Part I, LNCS 7076, pp.381-388,2011, Springer-Verlog Berlin Heidelberg 2011.

[14] Bskshi, T.,SinhaRay, A., Sarkar, B., “ Exploratory Analysis of Project Selection through MCDM", ICOQM-10,June 28-30,2011, pp.-128-133.

[15] Bskshi, T., Sarkar, B., Sanyal, S.K., “ Vendor Selection in Supply-Chain Environment using Integrated Approach of SOWIA \& MOORA", Proceedings of the 2011 International Conference on Advances in Supply Chain and Manufacturing Management Kharagpur, India, December 16-18,2011.

[16] Zavadskas, E.K., Kaklauskas, A., Turskis, Z., Tamosaitiene, J., "Selection of the effective dwelling house walls by applying attributes values determined at intervals." Journal of Civil Engineering and Management, (2008c) ,14 (2), 85-93.

[17] Zavadskas, E.K., Turskis, Z., Tamosaitiene, J, Marina , V., " Multicriteria selection of project managers by applying grey criteria", Technological and Economic Development of Economy, ,(2008d) , 14(4) , 462- 477

[18] Zavadskas, E.K., Kaklauskas, A., Turskis, Z., Tamosaitiene, J, "Multi-attribute decision-making model by applying grey numbers", Informatica, (2009b), 20(2), 305-320

[19] [19] MacCrimon, K.R., Decision Making Among Multiple- Attribute Alternatives: A Survey and Consolidated Approach.RAND Memorandum, RM4823-ARPA. The Rand Corporation, Santa Monica, CA,(1968).

[20] Srinivasan, V., Shocker, A. D., “ Linear programming techniques for multidimensional analysis of privileged", Psychometrika, .,(1973), 38, 337-369.

[21] Turskis , Z., Zavadskas , E.K. “ A new Fuzzy Additive Ratio Assessment Method ( ARAS-F) . Case Study: The analysis of Fuzzy Multiple Criteria in order to select the logistic centers location" Transport 25(4), (2010), 423432.

[22] O. Bayazit, B. Karpak, An AHP application in vendor selection, in: ISAHP 2005, Honolulu, Hawaii, July 8-10, 2005, pp. 1-24.

[23] K.S. Bhutta, F. Huq, Supplier selection problem: a comparison of the total cost of ownership and analytic hierarchy process approaches, Supply Chain Management: An International Journal 7 (3) (2002) 126-135.

[24] M. Marufuzzaman, K.B. Ahsan, K. Xing, Supplier selection and evaluation method using analytical hierarchy process (AHP): a case study on an apparel manufacturing organization, International Journal of Value Chain Management 3 (2) (2009) 224-240

[25] W.-N. Pi, C. Low, Supplier evaluation and selection via Taguchi loss functions and an AHP, International Journal of Advanced Manufacturing Technology 27 (56) (2006) 625-630

[26] T.L. Saaty, the Analytic Hierarchy Process, McGrawHill, New York, 1980.

[27] T.L. Saaty, Decision Making in Complex Environments: The Analytic Network Process for Decision Making with Dependence and Feedback, RWS Publications, Pittsburgh, PA, 2001.

[28] F. Tahriri, M.R. Osman, A. Ali, R.M. Yusuff, A. Esfandiary, AHP approach for supplier evaluation and selection in a steel manufacturing company, Journal of Industrial Engineering and Management 01 (02) (2008) 54-76.

[29] J.Sarkis, S. Talluri, A model for strategic supplier selection, The Journal of Supply Chain Management: A Global Review of Purchasing and Supply (winter) (2002) $18-28$.

[30] O. Bayazit, Use of analytic network process in vendor selection decisions, Benchmarking: An International Journal 13 (5) (2006) 566-579.

[31] F.T.S. Chan, Interactive selection model for supplier selection process: an analytical hierarchy process 
approach, International Journal of Production Research 41 (15) (2003) 3549-3579.

[32] C. Kahraman, U. Cebeci, Z. Ulukan, Multi-criteria supplier selection using fuzzy AHP, Logistics Information Management 16 (6) (2003) 382-394.

[33] M.Y. Bayrak, N. C, elebi, H. Tas, kin, A fuzzy approach method for supplier selection, Production Planning \& Control 18 (1) (2007) 54-63.

[34] M. Bevilacqua, A. Petroni, From traditional purchasing to supplier management: a fuzzy logic-based approach to supplier selection, International Journal of Logistics Research and Applications 5 (3) (2002) 235-255.

[35] A.F. Guneri, A. Yucel, G. Ayyildiz, An integrated fuzzyLP approach for a supplier selection problem in supply chain management, Expert Systems with Applications 36 (5) (2009) 9223-9228

[36] G. Tuzkaya, A. Ozgen, D. Ozgen, U.R. Tuzkaya, Environmental performance evaluation of suppliers: a hybrid fuzzy multi-criteria decision approach, International Journal of Environmental Science and Technology 6 (3) (2009) 477-490.

[37] J. Razmi, H. Rafiei, M. Hashemi, Designing a decision support system to evaluate and select suppliers using fuzzy analytic network process, Computers \& Industrial Engineering 57 (4) (2009) 1282-1290.

[38] Sreekumar, S.S. Mahapatra, A fuzzy multi-criteria decision making approach for supplier selection in supply chain management, African Journal of Business Management 3 (4) (2009) 168-177.

[39] M. Sevkli, S.C.L. Koh, S. Zaim, M. Demirbag, E. Tatoglu, Hybrid analytical hierarchy process model for supplier selection, Industrial Management \& Data Systems 108 (1) (2008) 122-142.

[40] J.-M. Ju, S.-G. Hwang, A study on supplier evaluation and selection method based on dependence, Journal of Advanced Computational Intelligence and Intelligent Informatics 8 (4) (2004) 415-420.

[41] M. Bevilacqua, F.E. Ciarapica, G. Giacchetta, A fuzzyQFD approach to supplier selection, Journal of Purchasing \& Supply Management 12 (2006) 14-27.

[42] [42] R.L. Armacost, P.J. Componation, M.A. Mullens, W.W. Swart, An AHP framework for prioritizing customer requirements in QFD: an industrialized housing application, IIE Transactions 26 (4) (1994) 72-79.

[43] A. Bhattacharya, B. Sarkar, S.K. Mukherjee, Integrating AHP with QFD for robot selection under requirement perspective, International Journal of Production Research 43 (17) (2005) 3671-3685.

[44] P.-T. Chuang, Combining the analytic hierarchy process and quality function deployment for a location decision from a requirement perspective, International Journal of Advanced Manufacturing Technology 18 (2001) 842849.
[45] Nnaji, B. O. and Yannacoupoulou, M., “ A utility theory based robot selection and evaluation for electronics assembly", Comp. Ind.Eng., 1988,14,477-493.

[46] Winston, W.L., The analytic hierarchy process. In Operations Research: Applications and Algorithms, edited by B. Wadsworth, pp.798-806,1994 ( Duxbury Press: Belmont, CA).

[47] Zadeh L., "Fuzzy sets", information control, vol 8, pp.338-53,1965.

[48] Huang C, Chu P, Chiang Y, "A fuzzy AHP application in government-sponsored $\mathrm{R} \& \mathrm{D}$ project selection" Omega 36 (2008) 1038-1052.

[49] Cheng CH, "Evaluating weapon systems using ranking fuzzy numbers", Fuzzy Sets and Systems, 1999, 107, pp 25-35.

[50] Van Laarhoven PJM, Pedrcyz W , “A fuzzy extension of Saaty's priority theory", Fuzzy Sets and Systems, 1983,11,pp-229-241.

[51] Da-Yong Chang, "Theory and Methodology Applications of the extent analysis method on fuzzy AHP", European Journal of Operational Research,(1996),95,649-655.

[52] Hauser, J.R. and Clausing, D., “ The house of quality", Harvard Business Review,1988,66(3),pp.-63-73.

[53] Ertay, T., "Simulation approach in comparison of a pull system in a cell production system with a push system in a conventional production system according to flexible cost: a case study", International Journal of Production Economics, 1998, 56-57, pp.-145-155.

[54] Chuang, P.T., "Combining the analytic hierarchy process and quality function deployment for a location decision from a requirement perspective", Int. J.Adv.Manuf. Technol., 2001, 18,842-849.

[55] Bakshi, T., Sanyal, S.K., "A Soft-Computing Approach for Software Project Selection", 2011 International Conference on Recent Trends in Information Systems,978-1-4577-0792-6/11/\$26.00@2011_IEEE, pp.-18-23.

[56] Bhattacharya, A., Sarkar, B. and Mukherjee, S.K., "Material handling equipment selection under multicriteria decision making (MCDM) environment",Ind.Eng. J., 2002, XXXI (6), 17-25.

[57] Bhattacharya ,A., Sarkar, B. and Mukherjee, S.K., "A holistic multi-criteria approach for selecting machining processes", in Proceedings of the $30^{\text {th }}$ International Conference on Computers \& Industrial Engineering, Tinos Island, Greece, 2002, Vol.1,pp. 83-88.

[58] Bhattacharya, A., Sarkar, B. and Mukherjee, S.K., "A new method for plant location selection: a holistic approach", Int. J. Ind. Eng.Theory Appl. Prac. , 2004, 11(4) , 330-338. 